\title{
Correction to: Turbulent Forced Convective Flows in a Horizontal Channel Provided with Heating Isothermal Baffles
}

\author{
Kamal Amghar, Louhibi Mohamed Ali, Salhi Najim, \\ and Salhi Merzouki
}

\section{Correction to:}

Chapter "Turbulent Forced Convective Flows in a Horizontal Channel Provided with Heating Isothermal Baffles" in:

M. Ezziyyani (Ed.): Advanced Intelligent Systems

for Sustainable Development (AI2SD'2018), AISC 912, https://doi.org/10.1007/978-3-030-12065-8_32

In the original version of this chapter, the following belated correction has been incorporated: The author's name was corrected from "Amghar Kamal" to "Kamal Amghar". The corrected book has been updated with the change. 